\title{
Fracture-Dislocations of Lisfranc Joint in Lomé (Togo)
}

\author{
Atchi Walla1 ${ }^{*}$, Anani Abalo1, Agbékponou Lagnéblé1, Sényo Tsolenyanu1, \\ Tchaa Towoezim1, N. K. Kombaté2, Michel Assang Dossim¹ \\ ${ }^{1}$ Service de chirurgie orthopédique et traumatologique, CHU Sylvanus Olympio, Lomé, Togo \\ ${ }^{2}$ Service de chirurgie orthopédique et traumatologique de l'hôpital Saint-Jean de Dieu d'Afagnan, Afagnan, Togo \\ Email: *atchi.walla@yahoo.fr
}

Received 15 December 2015; accepted 26 January 2016; published 29 January 2016

Copyright (C) 2016 by authors and Scientific Research Publishing Inc.

This work is licensed under the Creative Commons Attribution International License (CC BY).

http://creativecommons.org/licenses/by/4.0/

c) (i) Open Access

\section{Abstract}

Introduction: The purpose of this prospective study was to describe the clinic pathological varieties of fracture-dislocations of Lisfranc joint and outcome of treatment. Patients and Methods: This study was conducted on 21 cases of fracture-dislocations of the Lisfranc joint treated in our orthopedics trauma unit from 2010 to 2013 . We selected middle foot pure dislocations or associated with Lisfranc joint bone fractures. Classification of Myerson was used to characterize the lesions. The results assessment criteria were clinical and radiological for foot and Massari score. Results: Fourteen (14) patients were male. The average age was 34.7 years. Five (5) clinic pathological forms were met by relying on the classification of Myerson; 4 cases of type A; 5 cases of type B1; B2, 6 cases; 4 cases of type $C 1$ and 2 cases of type $C 2$. There were eight cases of pure dislocation and 13 dislocations were associated with fractures (metatarsal in 11 patients, cuneiform in 5 patients, cuboid bone in 2 patients and enucleation fracture of the medial cuneiform in 2 patients). It was noted 10 cases of skin openings. Treatment consisted on open reduction in all patients and stabilization by pin complemented by a foot plaster for 6 weeks. Four (4) immediately arthrodeses were made. All patients were followed up 7 month to 4 years (mean, 30 month). According to the criteria of Massiri, treatment outcomes were excellent in 19\% of cases, good in $28 \%$, fair in $30 \%$ and poor in $23 \%$. Conclusion: In our context, these lesions are often open and associated with fractures of Lisfranc joint skeleton and treated after a period more or less long and sometimes, we face lesions totally old. Immediately arthrodesis can be a lasting solution and should not be overlooked.

\section{Keywords}

Dislocation, Fracture, Lisfranc Joint, Pinning

\footnotetext{
*Corresponding author.
}

How to cite this paper: Walla, A., Abalo, A., Lagnéblé, A., Tsolenyanu, S., Towoezim, T., Kombaté, N.K. and Dossim, M.A. (2016) Fracture-Dislocations of Lisfranc Joint in Lomé (Togo). Open Journal of Orthopedics, 6, 16-21. 


\section{Introduction}

Lisfranc injuries account for approximately $0.2 \%$ of all fractures [1]. This frequency is underestimated because they are often ignored in the context of multiple traumas [2]. These are often severe lesions that can damage the structural integrity and mechanical midfoot in case of late diagnosis and management [3]. Early treatment is crucial for the final outcome [2]. Controversy exists regarding the optimal treatment of patients with Lisfranc injuries [1], and especially, in the affected joints with major damage and comminution [4]. Their gravity is related to the risk of osteoarthritis constitution with its impact on the foot function [5]. This risk is increased in open forms that are processed in a delayed manner as it is the case today in developing countries.

The purpose of this study was to describe the clinic pathological varieties and evaluate treatment.

\section{Material and Methods}

This work was conducted on fracture-dislocations of the Lisfranc joint treated in our orthopedic trauma unit from 2010 to 2013. Only tarsometatarsal dislocations isolated or associated with fractures of the bones of the Lisfranc joint treated and followed until the end of treatment in which the results were evaluated were included. The patients with Lisfranc fracture-dislocations who have not been monitored regularly until the end of treatment were not concerned. Clinical examination and X-rays of the foot from the foot of the front, side and three quarters allowed identifying the radiological forms and classifying lesions according to Myerson [6].

The surgical method involved a dorsal approach for reducing injuries and stabilization by pin complemented by a cast boot for six weeks. The therapeutic evaluation was based on clinical and radiological criteria thus obtaining the Massari Score [7]. Table 1 shows the clinical criteria used.

The radiological criteria were [8]:

- on incidence of face: the side edge of the first metatarsal aligned with the lateral edge of the medial cuneiform; the medial edge of the second metatarsal aligned with the medial border of the intermediate cuneiform; existence of gap between the medial cuneiform and the second metatarsal and/or between the first two metatarsals.

- on the incidence of three quarters: the side edge of the third metatarsal aligned with the lateral edge of the lateral cuneiform both dorsal surface at its plantar surface; the medial edge of the fourth metatarsal aligned with the medial edge of the cuboid bone; the side edge of the cuboid is the eighth note of the articular surface of the base of the fifth metatarsal.

Classification Myerson was used to characterize the lesions. The average follow-up was 30 months. The results assessment criteria were clinical and radiological foot and Massari score.

\section{Results}

Twenty-one (21) cases were reported. Fourteen (14) patients were male. The average age was 34.7 years. Traffic accidents were involved in all patients. The mechanism was direct in 13 patients (62\%). All lesions were unilateral. Three (3) patients (14.28\%) were multiple injuries and three others (14.28\%) were polyfractures. Five (5) clinic pathological forms (23.81\%) were met by relying on the Myerson classification. Table 2 shows the distribution of patients according to X-ray results.

There were eight (8) cases (38\%) of pure dislocation and in 13 patients (62\%) dislocation were associated with fractures (metatarsals in 5 patients, cuneiform in 3 patients, cuboid bone in 3 patients and fracture enucleation of the medial cuneiform in 2 patients).

Table 1. Clinical criteria.

\begin{tabular}{cccc}
\hline Pain & Absent & Light after prolonged walking & Severe and permanent \\
\hline Deformation & Absent & Dorsal deformation & Deformation in varus or in valgus \\
Heat & Absent & After prolonged walking & Severe and permanent \\
Plantar hyperheratosis & Absent & Present & Impossible \\
Lameness & Absent & Present & Possible with pain \\
Walking on tiptoe & Possible without pain & &
\end{tabular}


Table 2. Distribution of patients based on radiological forms encountered.

\begin{tabular}{ccc}
\hline & Cases number (n) & $\%$ \\
\hline Myerson A & 4 & 19.05 \\
Myerson B1 & 5 & 23.81 \\
Myerson B2 & 6 & 28.57 \\
Myerson C1 & 4 & 19.05 \\
Myerson C2 & 2 & 9.52 \\
Total & 21 & 100 \\
\hline
\end{tabular}

There were 10 cases (47.62\%) of skin opening (the Figure 1 shows a case of open fracture enucleation of medial cuneiform of left foot and the Figure 2, its X-ray aspect). The average time of care was 8 days (range 5 hours and 62 days).

The manual reduction under general anesthesia was attempted in 4 patients but was unsuccessful. All patients were treated by pinning after reduction as showed by Figure 3. Four (4) arthrodeses were immediately made.

All patients were followed between 7 months and 4 years (mean 30 months).

Table 3 shows the results according to clinical forms, radiological anatomy and the pure character of the associated dislocation or fracture of foot bones.

Depending on the support period, three of the four patients who presented excellent results have been processed before the 6th hour and 3 other 5 patients with poor outcome were treated surgically after six weeks. The four (4) patients treated with immediately arthrodesis, all reported results considered good. Global functional results are showed in Table 4.

\section{Ethical Aspects}

This study was authorized and conducted under the direction of the chief of orthopedic trauma unit of Sylvanus Olympio teaching hospital. Informed consent from study participants was obtained and the confidentiality of information collected has been preserved.

\section{Discussion}

This study, the first of its kind on the subject in the service, was prospective. However, the small sample size can lead to some conclusions. The X-ray of the foot alone is not enough in the comprehensive lesion assessment; Nunley JA [9] reported in 50\% patients, normal foot of unilateral X-ray in the presence of diastasis between the first two metatarsals thus obscuring the diagnosis. To avoid these diagnostic pitfalls, Benirschke SK [10] advised comparative X-ray of both feet. Also in our work, none of our patients had MRI which is sensible and specific exploration in the study of midfoot joint and above Lisfranc ligament according to Libby B [11].

Although the majority of these lesions (87\%) are closed [12], in our study, almost half of the lesions (47.62\%) were open and in over half the cases (62\%), they have been associated with fractures. This high incidence of fractures associated with open forms would be due to direct trauma most often involved in violent trauma, displacement mode using two-wheeled vehicles and the type of footwear of our environment; almost totally uncovered feet (not closed shoes) users are particularly vulnerable to these two-wheeled vehicles in the event of trauma. This is so true with direct shocks notion crushing of the foot which is the cause of damage of the soft tissues and bone fractures of Lisfranc joint.

The treatment of Lisfranc fracture-dislocations remains controversial today [13] outside the general consensus on the need for early diagnosis followed by anatomic reduction and rigid surgical stabilization [12] [14].

In recent forms diagnosed early, especially in the affected joints with major damage and comminution, two currents of followers seem to emerge [13]. On the one hand, advocates of open reduction and internal fixation home (ORIF) and on the other hand, users of primary arthrodesis. It has been shown that after treatment with ORIF, not only the Lisfranc ligament is not always healed but there was also an increase in joint degeneration and the onset of arthritis later require conducting secondary midfoot arthrodesis [1] [15]. Superior functional 


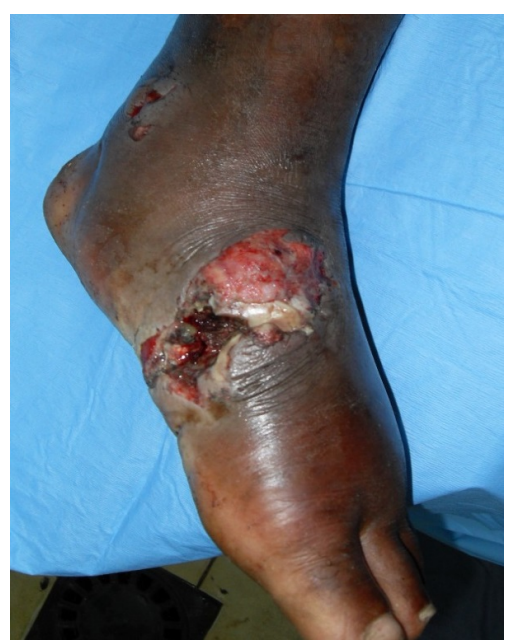

Figure 1. Aspect of left midfoot open fracture and medial cuneiform enucleation at third day after trauma.
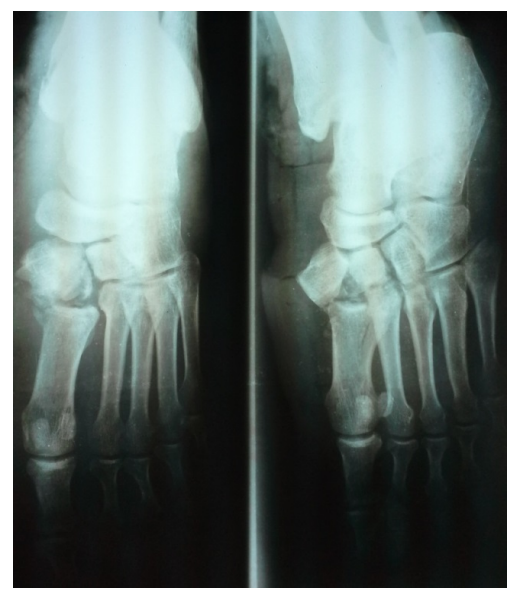

Figure 2. X-ray aspect of fracture and medial cuneiform enucleation of Figure 1.

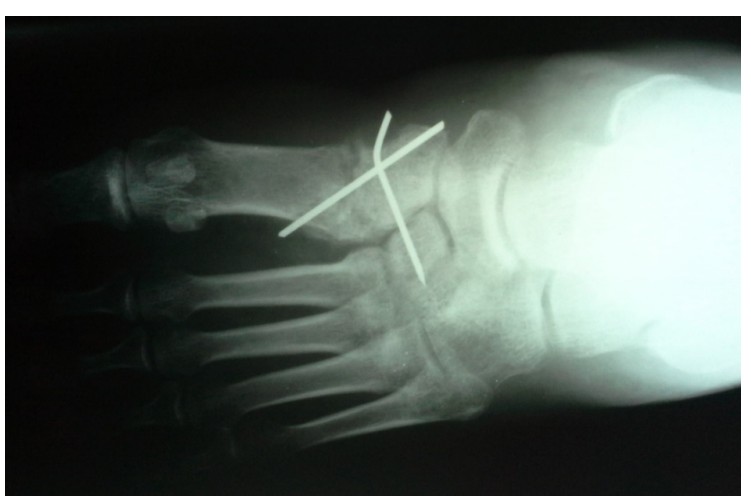

Figure 3. X-ray aspect of at the first postoperative day of the lesion showed by Figure 1.

outcome and lower rates of re interventions and complications have been reported with primary arthrodesis compared to treatment with ORIF [15] [16]. Our results seem to confirm this superiority of immediately arthrodesis because all of patients $(n=4 ; 19.05 \%)$ with immediately arthrodesis showed good results. These results 
Table 3. Results based on clinical forms, radiological anatomy and the pure character of the associated dislocation or fracture of foot bones.

\begin{tabular}{|c|c|c|c|c|c|}
\hline & Excellent & Good & Middle & Bad & Total \\
\hline Closed lesions & 2 & 3 & 4 & 2 & $11(52 \%)$ \\
\hline Open lesions & 2 & 3 & 2 & 3 & 10 (48\%) \\
\hline Myerson A & 2 & 1 & 1 & 0 & 4 \\
\hline Myerson B1 & 1 & 3 & 1 & 1 & 5 \\
\hline Myerson B2 & 1 & 2 & 2 & 1 & 6 \\
\hline Myerson C1 & 0 & 0 & 2 & 1 & 4 \\
\hline Myerson C2 & 0 & 0 & 0 & 2 & 2 \\
\hline Pur dislocation & & & & & $8(38.05)$ \\
\hline Fracture-dislocation & & & & & 13 (61.95) \\
\hline
\end{tabular}

Table 4. Sets out the overall results after therapeutic evaluation.

\begin{tabular}{ccc}
\hline & Cases number & (\%) \\
\hline Excellent & 4 & 19 \\
Good & 6 & 29 \\
Middle & 6 & 29 \\
Bad & 5 & 23 \\
Total & 21 & 100 \\
\hline
\end{tabular}

suggest that immediately arthrodesis in Lisfranc injuries can be a lasting solution for patients. Immediately arthrodesis is all the more interesting, it is often in our context, open lesions accompanied by joint damage treated after longer period (potential risk of developing osteoarthritis early post-traumatic and infection) or passed unnoticed and aged lesions.

\section{Conclusion}

Lisfranc fracture-dislocations are relatively rare and can be serious by providing chronic pain and functional impairment of the foot. In our context, they are often open lesions, associated with fractures of the skeleton of the Lisfranc joint and treated after a period more or less long and sometimes totally old lesions. Immediately arthrodesis can be a lasting solution and should not be overlooked.

\section{References}

[1] Sheibani-Rad, S., Coetzee, J.C., Givenas, M.R. and DiGiovanni, C. (2012) Arthrodesis versus ORIF for Lisfranc Fractures. Orthopedics, 35, e868-e873. http://dx.doi.org/10.3928/01477447-20120525-26

[2] Latoo, I.A., Wani, I.H., Farooq, M., Wali, G.R., Kamal, Y. and Gani, N.U. (2014) Midterm Functional Outcome after Operative Management of Midfoot Injuries. Ortopedia, Traumatologia, Rehabilitacja, 16, 639-644. http://dx.doi.org/10.5604/15093492.1135124

[3] Mittlmeier, T. and Beck, M. (2004) Tarsometatarsal Injuries-An Often Neglected Entity. Therapeutische Umschau, 61, 459-465. http://dx.doi.org/10.1024/0040-5930.61.7.459

[4] Welck, M.J., Zinchenko, R. and Rudge, B. (2015) Lisfranc Injuries. Injury-International Journal of the Care of the Injured, 46, 536-541. http://dx.doi.org/10.1016/j.injury.2014.11.026

[5] Dieme, C., Abalo, A., Badr, M., Sane, A., Dakoure, P., Ndiaye, A. and Seye, S. (2010) Luxations tarso-métatarsiennes à propos de 11 cas. J. Rech. Univ. Lomé (Togo), Série D, 12, 99-106.

[6] D-Myerson, M.S., Fisher, R.T., Burgess, A.R. and Kenzora, J.E. (1986) Fracture Dislocations of the Tarsometatarsal 
Joints: End Results Correlated with Pathology and Treatment. Foot Ankle, 6, 225-242. http://dx.doi.org/10.1177/107110078600600504

[7] Massari, L., Martinez, D., Flores, D. and Trainac, G. (1994) The Surgical Treatment of Fracture-Dislocation of the Lisfranc Joint. Foot Diseases, 1, 37-41.

[8] Saliou, G., Kocheida, M., Vernois, J., Bonnaire, B., Lehmann, P., Vanden Abeel, B., Boulu, G., Le Blanche, A.F. and Vallée, J.N. (2007) Aspects radiographiques des lésions ostéo-articulaires et ligamentaires des entorses de pied et de cheville. Journal de radiologie, 88, 541-547. http://dx.doi.org/10.1016/S0221-0363(07)89853-2

[9] Nunley, J.A. and Vertullo, C.J. (2002) Classification, Investigation, and Management of Midfoot Sprains: Lisfranc Injuries in the Athlete. American Journal of Sports Medicine, 30, 871-878.

[10] Benirschke, S.K., Meinberg, E., Anderson, S.A., Jones, C.B. and Cole, P.A. (2012) Fractures and Dislocations of the Midfoot: Lisfranc and Chopart Injuries. The Journal of Bone and Joint Surgery, 94, 1325-1337. http://dx.doi.org/10.2106/JBJS.L00413

[11] Libby, B., Ersoy, H. and Pomeranz, S.J. (2015) Imaging of the Lisfranc Injury. Journal of Surgical Orthopaedic Advances, 24, 79-82.

[12] Stavlas, P., Roberts, C.S., Xypnitos, F.N. and Giannoudis, P.V. (2010) The Role of Reduction and Internal Fixation of Lisfranc Fracture-Dislocations: A Systematic Review of the Literature. International Orthopaedics, 34, 1083-1091. http://dx.doi.org/10.1007/s00264-010-1101-x

[13] Watson, T.S., Shurnas, P.S. and Denker, J. (2010) Treatment of Lisfranc Joint Injury: Current Concepts. Journal of the American Academy of Orthopaedic Surgeons, 18, 718-728.

[14] Kuo, R.S., Tejwani, N.C., Digivanni, C.W., Holt, S.K., Benirschke, S.K., Hansen Jr, S.T., et al. (2000) Outcome after Open Reduction and Internal Fixation of Lisfranc Joint Injuries. Journal of Bone \& Joint Surgery, 82, 1609-1618.

[15] Sheibani-Rad, S., Coetzee, J.C., Givenas, M.R. and DiGiovanni, C. (2012) Arthrodesis versus ORIF for Lisfranc Fractures. Orthopedics, 35, e868-e873. http://dx.doi.org/10.3928/01477447-20120525-26

[16] Ly, T.V. and Coetzee, J.C. (2006) Treatment of Primarily Ligamentous Lisfranc Joint Injuries: Primary Arthrodesis Compared with Open Reduction and Internal Fixation. A Prospective, Randomized Study. Journal of Bone \& Joint Surgery, 88, 514-520. http://dx.doi.org/10.2106/JBJS.E.00228 